\title{
O desenho infantil: forma de expressão cognitiva, criativa e emocional
}

\author{
Alessandro Antonio Scaduto - FFCLRP-USP, Ribeirão Preto, Brasil
}

Weschler, S. M. \& Nakano, T. C. (2012). O desenho infantil: forma de expressão cognitiva, criativa e emocional. São Paulo, SP: Casa do Psicólogo.

A obra organizada por Solange M. Weschler e Tatiana C. Nakano aparece num momento de maior maturidade da Avaliação Psicológica no Brasil, em que questões historicamente polêmicas do campo podem ser abordadas a partir de pesquisas estruturadas e do resgate de estudos anteriores a esse período, considerados em termos de seus alcances e limites. Nesse sentido, o livro resgata dilemas importantes relativos à utilização dos desenhos para a avaliação infantil, atualizando tais dilemas a partir de pesquisas empíricas e revisões teóricas, visando demostrar as possibilidades das produções gráficas infantis para a avaliação psicológica nessa população.

Ao longo dos capítulos do livro, nota-se a busca por destacar o potencial do desenho infantil como forma de comunicação da criança, com diversas vantagens para a avaliação e intervenção. Ao mesmo tempo, a fundamentação do uso do desenho é enfatizada a partir de uma revisão dos autores que estudaram o tema ao longo da primeira metade do século XX, período rico em formulações teóricas e propostas técnicas, nem sempre acompanhadas de suporte empírico sólido. Tais limitações são objeto de revisão e pesquisas relatadas nas três partes do livro, referentes ao potencial do desenho infantil como meio de expressão (capítulos 1 e 2), seu uso na avaliação criativa e cognitiva (capítulos 3 a 5) e como facilitador da expressão emocional (capítulos 6 a 9).

$\mathrm{Na}$ primeira parte, os capítulos revisam os usos do desenho como forma de expressão humana, assim como sua apropriação ao longo da psicologia moderna e estudos atuais sobre o tema. Enquanto o primeiro capítulo (da autoria de Maria Lucia Tillet Nunes, Rita P. Teixeira, Cristiane Feil e Rafaele Paniagua) revisa aspectos históricos, o segundo capítulo, por Solange M. Weschler, trata do teste mais discutido ao longo do livro, o Desenho da Figura Humana (DFH), como meio de acessar aspectos referentes ao funcionamento cognitivo, criativo e emocional. Enquanto para os dois primeiros aspectos são mencionados trabalhos anteriores com sistemas de cotação do DFH (enfatizando o sistema desenvolvido por Solange Weschler para avaliação cognitiva), o último aspecto é discutido quanto às dificuldades em prover suporte empírico que possa ser generalizado para a população infantil, apontando para limitações metodológicas no campo da avaliação psicológica, em especial, a busca por significações unívocas de indicadores do desenho, por vezes isolados de seu contexto, estratégia empírica e epistemologicamente viável para a avaliação cognitiva e incompleta para a natureza dinâmica dos construtos comumente abordados na avaliação emocional dos desenhos infantis. Para lidar com tais dificuldades, são sugeridas pesquisas abordando escalas globais de avaliação, tendo em vista seu potencial demonstrado na literatura internacional, tema que é retomado na terceira parte do livro.

A segunda parte (caps. 3 a 5) aborda o desenho como estratégia de avaliação criativa e cognitiva, apresentando pesquisas clássicas no Brasil e exterior, além dos esforços mais recentes nessas áreas. Dois dos capítulos dessa parte apresentam a fundamentação teórica e empírica de técnicas gráficas para avaliação da criatividade, com ênfase no Teste da Criatividade Figural Infantil no capítulo 3 (por Tatiana C. Nakano) e no Sistema de Pontuação Gradual do Teste de Bender (Bender - SPG), para avaliação da maturidade perceptomotora (capítulo 5, por Ana Paula P. Noronha, Acácia A. dos Santos e Fabían J. M. Rueda). Esses capítulos acabam funcionando como uma apresentação de tais testes, que se encontram com parecer favorável no SATEPSI, assim como uma breve atualização das pesquisas com os mesmos. O capítulo 4, da autoria de Simone F. S. Domingues, Irai Cristina B. Alves, Helena R. Rosa e Renan A. Sargiani, oferece um resgate de técnicas gráficas estudadas no contexto sociocultural brasileiro nas décadas de 1960 a 1980, apontando para a importância de que a pesquisa com as mesmas seja retomada, visando desenvolver alternativas para as ainda escassas opções de avaliação infantil, especialmente aquelas que permitem conhecer o funcionamento emocional de crianças a partir de procedimentos padronizados e estudados em nosso contexto.

A terceira parte do livro aborda as pesquisas sobre a avaliação do funcionamento emocional com base nos desenhos infantis. Se, por um lado, as autoras desses capítulos destacam a riqueza da produção gráfica como forma de acesso aos conteúdos afetivos e fantasias infantis, a necessidade de adequado suporte empírico e o recurso a várias e contextualizadas fontes de informação é enfatizado, objetivando superar o risco 
de uma avaliação subjetivamente orientada, a qual pode apresentar diversas falhas em relação à sua validade $\mathrm{e}$ fundamentação. Nesse sentido, as autoras do capítulo 6 (Joice D. Segabinazi e Denise R. Bandeira) afirmam que as impressões clínicas, comumente referidas como critério de validade para as intepretações do desenho infantil (e mais especificamente, do DFH), podem estar embasadas por pressupostos errôneos e para evitar tal engano, escalas globais derivadas de estudos empíricos se mostram mais adequadas, como demonstrado a partir do estudo empírico relatado ao longo do capítulo. Tal crítica é fundamental, pois permite superar o risco de vieses da análise do DFH baseada apenas na experiência clínica do profissional, e não se opõe à noção de validade clínica, que é abordada e adequadamente contextualizada em todos os momentos em que tal conceito é citado, ao longo de toda a obra.

O capítulo 7, da autoria de Roselaine B. F. da Silva, Emanueli Paludo e Vivian S. da Costa, é dedicado ao DFH na chuva, revitalizando a pesquisa com essa técnica fundamentada em estudo empírico que demonstra seu potencial para a identificação de características de personalidade e manejo das vivências afetivas em crianças a partir de oito anos (já que seu estudo mostrou menos sensibilidade a tais variáveis em crianças menores). Os capítulos finais, elaborados, respectivamente, por Valéria Barbieri, Fernanda K. T. Mishima e Sonia R. Pasian (capítulo 8) e Tânia Maria J. Aiello Vaisberg e Fabiana Follador e Ambrosio (capítulo 9), apresentam contribuições baseado em modelos psicodinâmicos, destacadamente, da obra de Donald W. Winnicott. O capítulo 8 discute as vantagens do Desenho de Famílias com Estórias (DFE) para a investigação dos psicodinamismos da tendência antissocial, a partir de uma revisão das características das pesquisas com base no método psicanalítico e estudos de casos em diferentes investigações conduzidas pelo grupo de pesquisa da primeira autora do capítulo. Já o último capítulo da obra oferece reflexões sobre o uso do desenho infantil para a compreensão do comportamento saudável, a partir da produção gráfica de uma criança de três anos vinda de uma família aguardando o segundo filho.

$\mathrm{O}$ livro é indicado não apenas àqueles interessados nos desenhos infantis como estratégia de avaliação, mas a todos que desejem conhecer questões pertinentes à área de Avaliação Psicológica no Brasil atualmente, mostrando os esforços organizados de pesquisadores brasileiros em demonstrar as possibilidades da análise de desenhos infantis em nosso contexto a partir dos conhecimentos existentes sobre o tema, apresentando resultados encorajadores e desafios a serem superados.

Sobre o autor:

Alessandro Antonio Scaduto é psicólogo, mestre e doutorando em Psicologia pela FFCLRP-USP, atuando nas seguintes áreas: Avaliação Psicológica, Orientação Profissional e Psicologia Sociocomunitária. Foi bolsista CAPES e atualmente é bolsista FAPESP, ligado ao Centro de Pesquisas em Psicodiagnóstico - FFCLRP-USP.

\section{Contato com o autor:}

Faculdade de Filosofia, Ciências e Letras de Ribeirão Preto - Universidade de São Paulo

Tv. Alvorada, 77 - Sumarezinho - CEP 14051-298 - Ribeirão Preto/SP, Brasil

E-mail: aascaduto@uol.com.br 